\title{
Introduksi Nilai-Nilai Lokal Pada Pemasaran Minyak Kelapa Khas Mandar
}

\author{
Introduction of Local Values To The Marketing of Mandar Typical Coconut Oil \\ Musmawati $^{1 *}$ Irmayani $^{1}$, Abdul Azis Ambar ${ }^{1}$ \\ Email: musmawati85@gmail.com \\ ${ }^{1}$ Program Studi Agribisnis, Program Pascararjana, Universitas Muhammadiyah Parepare
}

Diterima: 01 Mei 2021 / Disetujui: 02 Agustus 2021

\begin{abstract}
ABSTRAK
Jenis penelitian ini adalah penelitian kualitatif dimana dalam mendapatkan data menggunakan beberapa metode seperti metode wawancara, dokumentasi, observasi dan dokumentasi dimana data yang didapatkan dikelolah dengan cara mereduksi data kemudian menyajikan data dan melakukan pengambilan kesimpulan. Hasil penelitian ini menunjukkan bahwa Introduksi nilainilai lokal pemasaran minyak kelapa mandar terdapat pada acara adat pernikahan mandar yaitu Maccanring dan Metindor.Keluarga mempelai laki-laki biasanya membawa pakaian shalat, lemari, peralatan dapur, peralatan mandi, kelapa, buah-buahan serta minyak kelapa mandar.Menggunakan promosi dalam pemasaran minyak kelapa mandar dengan landasan meningkatkan nilai-nilai lokal.Introduksi nilai-nilai lokal masih sangat dibutuhkan pengelolah minyak kelapa mandar pada kondisi saat ini.Perkembangan teknologi dan komunikasi berpengaruh terhadap strategi perencanaan pemasaran. Dan Pelaksanaan strategi pemasaran berdasarkan prinsi-prinsip nilai lokal yang diterapakan dalam berbisnis boleh saja mencari keuntungan sebanyak-banyaknya asal jangan sampai merugikan konsumen ataupun pedagang lain. Cara berdagang sesuai denganJujur dalam menakar dan menimbang, halal, baik mutu atau kualitas minyak kelapa mandar.
\end{abstract}

Kata Kunci: Nilai-Nilai Lokal,Pemasaran Minyak Mandar, Pemaknaan Tindakan

\begin{abstract}
The type of research is gualitative research where obtaining data using sereval methods ,observation, where the data obtained. Based on the results of the study,shows that the introduction of the local value of mandar Coconut oil,marketing can be found at the mandar wedding ceremony namely'Maccanring and metindor ".The groom's family usually brings prayer clothes ,cupboards,kitchen utensil,toiletries, Coconut,fruits and mandar Coconut Oil.Using promotion in the marketing of mandar Coconut oil in the basic of increasing the introduced local values.Local values are still very much needed by mandars coconut oil processor at current conditions. The development of technology and communication affects the marketing planning strategy and the implementation of marketing strategis based on principles of local values that are applied is doing bussines, it is possible to seek as much profil as possible as long as it does not harm consumers or other traders. How to trade in accordance with Islamic principles,namely honestly and measuring and weighing, halal both qualityor quality of mandar coconut oil
\end{abstract}

Keynotes : Local Wisdom, Marketing of Mandar Coconut oil, Meaning of The Action

This work is licensed under Creative Commons Attribution License 4.0 CC-BY International license 


\section{A. PENDAHULUAN}

Tanaman kelapa dimanfaatkan hampir semua bagiannya oleh manusia sehingga dianggap sebagai tumbuhan serba guna, khususnya bagi masyarakat pesisir.Keunggulan lokal setiap daerah satu berbeda dengan lainnya,(Santoso 2014),menyatakan bahwa keunggulan lokal dapat lahir sesuai kondisi geografis,natural mengacu pada nilai-nilai unggulan dari budaya-budaya lokal yang selanjutnya menjadi warisan budaya bangsa Indonesia.Minyak Mandar adalah minyak berbahan kelapa (coconut oil) merupakan warisan nenek moyang yang memiliki nilai etnis budaya yang tinggi juga memiliki aroma/bau khas dari minyak kelapa.

Penelitian ini bertujuan untuk mengetahui cara introduksi nilai-nilai lokal pada pemasaran minyak kelapa khas mandar dan untuk mengetahui sistem pemasaran berdasarkan prinsip-prinsip nilai lokal yang diterapakan.

\section{B. METODE PENELITIAN}

Penelitian ini akan dilaksanakan di Kelurahan Manding,Kecamatan Polewali Kabupaten Polewali Mandar dari Bulan Juli s/d bulan Desember 2020,Pemilihan lokasi ini dengan pertimbangan bahwa Kelurahan Manding merupakan pusat penghasil minyak Kelapa khas Mandar di Polewali

Bentuk atau Jenis penelitian ini adalah penelitian yang bersifat kualitatif. untuk desain penelitian yang digunakan yaitu deskriptif kualitatif. Data digali dari informan baik berupa pernyataan lisan maupun tulisan dan tindakan atau sikap yang dapat diamati oleh peneliti.Kata-kata dan tindakan dari individu yang menjadi objek penelitian atau informan adalah basis data dalam penelitian kualitatif yang akan dianalisis untuk menjawab sejumlah pertanyaan penelitian yang telah diajukan. Sementara data lainnya bersifat data perorang yang dianggap memiliki kemampuan khusus berupa dokumen tertulis dan foto.

\section{HASIL DAN PEMBAHASAN}

Pemasaran minyak mandar adalah suatu yang sangat penting untuk memperkenalkan produk asli daerah tersebut tentunya dalam pemasaran harus ditunjang dengan perencanaan yang baik pula, namun hasil penelusuran yang peneliti dapatkan dilapangan diperoleh informasi bahwa para pembuat minyak melakukan perencanaan yang terstruktur, berdasarkan informasi yang diperoleh bahwa :

Hasil wawancara Rasadiah: Kami dalam memasarkan minyak mandar tidak 
punya perencanaan yang terstruktur sebab sebelum membuat minyak kami hanya menyiapkan kelapa untuk dibuat.

Hal tersebut senada dengan apa yang disampaikan oleh Hasil wawancara dengan Lipa: Kalau masalah perencanaan yang secara matang, sebenarnya tidak ada karena kita hanya siapkan kelapa yang sudah dipanen dikebun atau hasil dari pembelian dari masyarakat sekitar baru kita membuat minyak, lagian kami juga mengangap bahwa kalau sudah dibuat sudah ada yang siap untuk membeli.

Hasil wawancara yang peneliti peroleh diatas bahwa para pembuat minyak kelapa mandar tidak melakukan perencanaan secara sistematis sebab semua hanya mengalir sesuai dengan kebiasaan yang mereka lakukan sebab mereka menganggap bahwa apabila sudah ada minyak yang sudah dibuat pembeli sudah ada yang siap untuk mengambil minyak tersebut.

Hasil wawancara Rasadiah (1) menyatakan bahwa.Mengenai pentingnya introduksi nilai-nilai lokal pamasaran minyak kelapa mandar digunakan dalam acara adat pernikahan mandar termasuk maccanring

Hasil wawancara peneliti berpendapat bahwa acara maccanring biasanya laki-laki membawa buahbuahan, kue serta minyak kelapa mandar. Maccanring merupakan mengantar uang belanja dan seluruh bahan yang akan dipakai dalam pesta perkawinan kepada pihak perempuan.

Hasil wawancara Naju

diperoleh. Introduksi nilai-nilai budaya lokal memasarkan minyak kelapa mandar dapat juga dilakukan pada proses Metindor dalam kegiatan adat pernikahan mandar.

$$
\text { Hasil wawancara penulis }
$$
berpendapat salah satu cara introduksi nilai-nilai lokal pemasaran minyak kelapa mandar, terdapat pada acara adat pernikahan mandar yaitu metindor, dimana masyarakat awan biasanya menyebut kalau metindor itu merupakan arak-arakan dengan pakaian adat, mengantar calon mempelai laki-laki kerumah calon mempelai perempuan.

Hasil wawancara Lipa (3) di peroleh.Pembeli datang sendiri dan masyarakat tidak mempunyai perencanaan strategi introduksi nilai-nilai lokal pada pemasaran Minyak kelapa khas mandar karena pembeli sudah tahu dari dulu sejak jaman belanda jadi minyak mandar itu sudah banyak dikenal oleh semua orang sejak dahulu kala. 
Berdasarkan hasil wawancara peneliti memahahami bahwa konsumen sudah mengetahui tempat untuk membeli minyak kelapa mandar. Strategi pemasaran harus menganalisis kekuatan dan kelemahannya untuk menentukan peluang menarik yang dapat diperoleh dengan baik.

Hasil wawancara Hi'da diperoleh. Tahap evaluasi dalam strategi pemasaran menempatkan loyalitas konsumen sebagai tujuan akhir.

Berdasarkan hasil wawancara peneliti memahami dalam pelaksanaan pemasaran suatu perusahaan dapat sukses dalam persaingan adalah dengan berusaha mempertahankan pelanggan dan mencapai tujuan untuk menciptakan konsumen yang loyal menggunakan minyak kelapa mandar.

Hasil waawancara Kinda (5) di peroleh. Menganalisa kondisi pasar dalam introduksi nilai-nilai lokal pada pemasaran minyak kelapa khas mandar dengan cara menentukan pasar yang relevan.

Berdasarkan hasil wawancara peneliti memahami bahwa Pemasaran minyak kelapa khas mandar pada tempat keramaian memberikan pengaruh serta daya tarik terhadap introduksi nilai-nilai lokal.
Hasil wawancara Nurlina diperoleh. Menganalisis kondisi pasar dalam introduksi nilai-nilai lokal pada pemasaran minyak kelapa khas mandar dengan cara menganalisa permintaan primer.

Berdasarkan hasil wawancara peneliti memahami bahwa meningkatnya konsumsi dalam negeri maupun permintaan global merupakan peluang produksi primer kelapa.

Hasil wawancara Saharia (7) diperoleh. Menganalisa kondisi pasar dalam introduksi nilai-nilai lokal pada pemasaran minyak kelapa khas mandar dengan cara menetapkan segmen pasar.

Berdasarkan hasil wawancara peneliti berpendapat penentuan posisi pasar penting dilaksanakan mulai merencanakan segmen pemasaran.

Hasil wawancara salma diperoleh. Menganalisa kondisi pasar dalam introduksi nilai-nilai lokal pada pemasaran minyak kelapa khas mandar dengan cara menganalisa persaingan dan Identifikasi target potensial.

Berdasarkan hasil wawancara peneliti berpendapat persaingan cara yang dilakukan mengintroduksikan minyak kelapa mandar tetap mengutamakan prinsip Islami tentang sistem pemasaran atau penjualan. 
Hasil wawancara Isa Agusnaeni (9) diperoleh Analisa SWOT introduksi nilainilai lokal pada pemasaran Minyak kelapa khas mandarkepada masyarakat tujuannya adalah untuk menentukan aspek-aspek penting dari kekuatan,kelemahan,peluang dan ancaman di masyarakat sehingga apa yang direncanakan dapat tercapai.. Berdasarkan wawancara peneliti memahami adanya analisis SWOT sebelum melakukan introduksi nilai-nilai lokal minyak kelapa khas mandar, yaitu kekuatan (Strength) merupakan kondisi internal menunjang suatu organisasi agar mencapai objektif yang diinginkan.

$$
\text { Hasil wawancara Salma }
$$

diperoleh.

Nilai-nilai

kesabaran,ketabahan,kegigihan lokal diperkenalkan dalam pemasaran minyak kelapa khas mandar.

Berdasarkan wawancara peneliti memahami proses pemasaran produk Janganlah jenuh terhadap sesuatu yang lihat dilakukan salah satu konsumen mungkin dapat menyakitkan hati, tetapi bersabarlah menghadapnya.

Ketabahan memasarkan produk minyak kelapa adalah usaha sadar serta terencana dalam sikap agar mengenal, memahami, bertakwa, dan berakhlak mulia dalam mengamalkan ajaran agama Islam dari sumber utamanya kitab suci al-
Qur'an dan hadis, melalui kegiatan jualbeli dalam perdagangan.

Kegigihan dimulai dari proses pembuatan atau pengolahan sampai pada pemsaran, nilai lokal yang pertama serta utama dilakukan sebagai produsen pada bidang ekonomi selalu melakukan pekerjaan sungguh-sungguh serta semangat memasarkan atau menjual produk. Selai hasil wawancara yang penulis temukan selama berada dilokasi penelitian peneliti juga menemukan beberapa data terkait beberapa hal yang terkait dengan nilai-nilai lokal sebagaimana hasil wawancara berikut ini : Rasadiah diperoleh , Pada saat penjualan minyak, saat penjual mengisi botol, mereka jarang sekali ada yang mau berbicara, maknanya adalah untuk menjaga kebersihan minyak karena jangan sampai ada air liur yang jatuh pada minyak yang sangat diagungkan.

Naju diperoleh : Pada saat menjual dan mengisi botol dan saat selesai mengisinya mereka menempelkan kedinding jari mereka agar melihat hitungan minyak, dengan maksud agar tidak terjadi kesalahan dalam menghitung jumlah minyak (berapa botol) dan sebagai maknanya adalah senantiasa menjaga kejujuran dalam memasarkan minyak mandar. 
Lipa diperoleh : Apabila ada pembeli yang memesan untuk pengantin dan saat itu saat itu pesanan minyak belum diambil, biasanya minyak tersebut disimpan dilemari yang baik dan tidak boleh diganggu dengan maksud nenek moyang berdoa dan turun temurun sampai sekarang agar sipengantin kelak bahagia dan rumah tangganya seharum minyak mandar tersebut

Hi'da diperoleh informasi :Pada saat menjual banyak juga konsumen membeli minyak mandar untuk anak bayi dan balita dengan maksud agar rambut anak tersebut hitam, lebat dan murah rejekinya kelak.

Isa Agusnaeni diperoleh informasi :Pada saat penjualan banyak yang pesan atau langsung membeli dijadikan sebagai obat gatal, ini menadakan bahwa minyak mandar memiliki nilai lebih karena dapat menobati gatal sekligus didalamnya ada nilai mistis karena minyak tersebut dibacakan do'a oleh orang-orang tertentu,

Kinda diperoleh informasi :Minyak mandar ada juga yang dijadikan sebagai minyak urut ini sekaligus menandakan bahwa minyak mandar begitu diagungkan karena sangat berkhasiat baik dari segi medis maupun spiritual yang dibuat khusus oleh orang yang dianggap pintar.

Nurlina diperoleh informasi :Pada penjualan minyak mandar, minyak tersebut juga dijadikan obat panas anak.

Saharia diperoleh informasi Pada saat menjual tidak boleh menggarukgaruk dan berpegangan kesembarang tempat dengan tujuan menjaga kebersihan adanya daki dan kotoran yang masuk keminyak karena keagungannya sangat dipertahankan.

Hasil wawancara dari beberapa informan diatas menunjukkan bahwa minyak mandar adalah salah satu produk lokal yang ada di Polewali Mandar ini dapat dilihat Pada saat minyak akan dijual, sebelummnya dimasukkan kedalam botol dan para penjual tidak ingin banyak berbicara, dengan alasan bahwa minyak mandar harus senantiasa dijaga dari kotoran yang dapat keluar dari mulut sipembuat. Disamping itu para pembuat minyak senantiasa menghitung jumlah takaran dengan cara tradisional yaitu dengan menempelkan jari kedinding dengan tujuan menjaga kepercayaan pembeli dan senantiasa menjaga nilai kejujuran dalam berdagang. Selain itu minyak mandar biasa dijadikan sebagai minyak rambut dan minyak urut bayi, ini menandakan bahwa di daerah tersebut sangat mengagungkan atau menjaga minyak mandar.

Hasil wawancara Ristina 
diperoleh.pentingnya strategi pemasaran yang berdasarkan prinsi-prinsip nilai lokal yang diterapakan adalah mendapatkan keuntungan besar dan meningkatkan penjualan.

Berdasarkan wawancara peneliti memahami meningkatkan penjualan minyak kelapa dengan cara menerapkan strategi promosi dalam bentuk publikasi dengan aktif memposting di sosial media.

Hasil wawancara Sanang (12) diperoleh.Pelaksanaan strategi pemasaran berdasarkan prinsi-prinsip nilai lokal yang diterapakan dalam berbisnis boleh saja mencari keuntungan sebanyak-banyaknya asal jangan sampai merugikan konsumen ataupun pedagang lain. Cara berdagang saya sudah sesuai dengan nilai-nilai lokal Jujur dalam menakar dan menimbang, halal, baik mutu atau kualitas minyak kelapa mandar.

Berdasarkan wawancara penulis memahami para pedagang minyak kelapa mandar mengenai strategi dagang dalam perspektif nilai lokal baik. Tidak ingin melakukan kecurangan bukan hanya karena takut kehilangan pembeli, akan tetapi mengaku takut kepada Allah Swt.

Hasil wawancara Ani(13) diperoleh. Semua perencanaan strategi belum terimplementasi sesuai dengan perencanaan awal.Berdasarkan wawancara peneliti berpendapat tidak semua rencana akan terealisasikan. Implementasi pemasaran merupakan tahap pelaksanaan dari tahap strategi pemasaran, dalam tahap tersebut terdapat implementasi dari unsur pemasaran (produk, harga, tempat dan posisi) serta unsur promosi (periklanan, promosi penjualan, hubungan masyarakat, penjualan personal, pemasaran langsung).

$$
\text { Hasil wawancara Hasni }
$$
diperoleh.Mereka tidak melakukan promosi tapi orang-orang sudah tahu dari dulu sejak jaman pemjajahan belanda tentang minyak mandar jadi dipromosikan atau tidak tentunya orang sudah banyak mengetahui bahwa di Mandar terdapat minyak mandar.

Berdasarkan wawancara peneliti memahami pentingnya promosi produk minyak kelapa mandar agar masyarakat diluar Sulawesi barat mengetahui adanya minyak tersebut.

Hasil wawancara Anita diperoleh Pedagang melakukan promosi tentang minyak mandar pada sosial media social yang dimiliki seperti media facebook dan whatshap dan berbagai media social lainnya.

Berdasarkan wawancara peneliti memahami penggunaan promosi dengan iklan dilakukan berbagai media sosial 
seperti Facebook, WhatsApp dan instagram. Tujuan promosi lewat iklan merupakan berusaha agar menarik serta memengaruhi calon konsumen.

Hasil wawancara Rasadiah(16) diperoleh Evaluasi kerja pada pemasaran berdasarkan prinsi-prinsip nilai lokal yang adanya perubahan kondisi dan situasi pasar serta perekonomian dimana pasar semakin berkembang ,teknologi berubah dan pesaing-pesaing baru bermunculan, Semakin rumit dan kompleksnya aktivitas masyarakat,maka dibutuhkan suatu control yang lebih baik, Semakin terdesentralisirnya kekuasaan dan wewenang, Dapat mengetahui sejauh mana program sehingga pengusaha dapat melakukan aksi koreksi yang diperlukan dan Memastikan penggunaan sumber daya yang efektif dan efisien. Mengevaluasi sejauh mana memiliki dampak yang diinginkan

Berdasarkan wawancara peneliti berpendapat pesaing baru merupakan ancaman dalam persaingan usaha pembuatan minyak kelapa.

$$
\text { Hasil wawancara Naju }
$$

diperoleh Masyarakat tidak melakukan evaluasi strategi setiap berkala dalam pemasaran

$\begin{array}{crr}\text { Berdasarkan } & \text { wawancara } & \text { peneliti } \\ \text { memahami } & \text { masyarakat } & \text { harus }\end{array}$

mengevaluasi setiap pemasaran minyak kelapa mandar.

$$
\text { Hasil wawancara Lipa }
$$

diperoleh.Evaluasi strategi dilakukan oleh masyarakat dapat mencapai target yang telah ditentukan pemasaran yang dilakukan masih lokal atau kedaerahan. Berdasrkan wawancara peneliti berpendapat meningkatnya konsumen menggunakan produk minyak kelapa mandar sebagai bentuk budaya lokal atau kedaerahan.

Semakin baik minyak kelapa mandar, maka semakin besar pula keputusan konsumen atau pemakai terhadap minyak kelapa mandar, begitu sebaliknya.

\section{KESIMPULAN DAN SARAN}

Hasil penelitian dapat disimpulkan bahwa introduksi nilai-nilai lokal pada pemasaran minyak kelapa Khas mandar, terdapat pada acara adat pernikahan mandar yaitu Maccanring dan Metindor. Sistem pemasaran berdasarkan prinsipprinsip nilai local, Strategi pemasaran berdasarkan prinsip-prinsip nilai lokal yang diterapakan . Cara berdagang Jujur sesuai prinsip islam

\section{DAFTAR PUSTAKA}

Agustinus Sri Wahyuni, 1996, Manajemen Strategik, Binarupa Aksara, Jakarta. 
Anonim, kabupaten Polewali Mandar, http://id.wikipedia.org

Anonim, Kelapa Sawit Idola yang Tertuduh, http//www. Kpbptn. co. id

Boyd, Harper W. 2000. Manajemen Pemasaran "suatu pendekatan strategis dengan orientasi global", Jakarta : Erlangga

Fandy Tjiptono, 2008, Pemasaran Jasa,Bayumedia, Malang.

Husaini Usman dan Purnomo Setiady Akbar, 2003.Metodologi Penelitian Sosial Cet. IV; Jakarta: Bumi Aksara,

Irmayanu,Spiritualitas, Rasionalitas dan keberlanjutan pertanian (studi Fenomenologi Komoditas petani di Desa Bone-Bone ,Kabupaten Enrekang) 2016

Ing. Sukamdiyo, 1996, Manajemen Koperasi, Erlangga, Jakarta.

J. Winardi, 2003, Entrepreneur \& Entrepreneurship, Kencana, Bogor.

Jhon W. Creswell, Research Design, Pendekatan Kualitatif, Kuantitatif, dan Mixed, trans. oleh Achmad Fawaid, Cet. VI, Yogyakarta: Pustaka Pelajar, 2017

Jurnal AGRIFOR Volume XII Nomor 1, Maret 2013

Koentjaraningrat, 1974, Pengantar Antropologi. Jakarta: Aksara Baru.

Kompas, Mengenal Jenis Minyak Kelapa, http//www.Kompas.com. diakses pada tanggal 20 November 2019

Kotler,Philip.1997, Manajemen Pemasaran. Edisi Bahasa Indonesia jilid satu. Jakarta: Prentice.

Moertjipto, dkk. 1997. Wujud, Arti dan Puncak-Puncak Kebudayaan Lama dan Asli bagi Masyarakat Penorang yang dianggap memiliki kemampuan khususnya. Departemen Pendidikan dan Kebudayaan DIY
Muhaimin, 2001. Islam dalam Bingkai Buduaya Lokal;Potret dari Cirebon, Jakarta : Logos.

Pandji Anoraga, 1997, Manajemen Bisnis, Rineka Cipta, Jakarta.

Perspektif Vol. 6 No. 2 / Desember 2007.

Philip Kotler dan Kevin Lane Keller, 2009, Manajemen Pemasaran, alih bahasa Benyamin Molan, Macanan Jaya Cemerlang, Indonesia.

Philip Kotler, Kevin Lane Keller, 2008, Manajemen Pemasaran, edisi 13 jilid 1, Jakarta,Erlangga.

Tasmuji, Dkk,2011.Ilmu Alamiah Dasar, Ilmu Sosial Dasar, Ilmu Budaya Dasar, Surabaya: IAIN Sunan Ampel Press.

Turukay, Marta. 2008. Analsisi Permintaan Ekspor Kopra Indonesia di Pasar dunia. Jurnal Agroforestri, $3(2)$.

Wijaya, Hengki. Prasetyo., Soetoro, dan Tito Hardianto. 2016. Analisis Saluran Pemasaran Kopra (Studi Kasus di Desa Sindangsari Kecamatan Cimerak Kabupaten Pangandaran).

Wulandari, Siti. Abir. 2018. Kontribusi Pendapatan Usaha Kopra terhadap Pendapatan Rumah Tangga Petani di Kabupaten Tanjung Jabang Timur. Jurnal Media Agri Bisnis,3. 